\title{
Effect of punishment on extinction of an avoidance response: Facilitation or inhibition?'
}

NELSON F, SMITH, ${ }^{2}$ JAMES R. MISANIN AND BYRON A. CAMPBELL

PRINCETON UNIVERSITY

The present study varied intensity and duration of punishment and level of training in an attempt to produce facilitation of responding by punishment during extinction of an avoidance response. Animals were trained to avoid shock in a shuttlebox to a criterion of 2,4 , or 8 consecutive avoidance responses. The $S$ s were then put on a punishment-extinction schedule. Five intensities and two durations of punishment were used. No evidence for facilitation by punishment was found. Inhibition of responding was directly related to both intensity and duration of punishment but unrelated to level of training.

Under what conditions does punishment facilitate avoidance responding during extinction and under what conditions does it inhibit responding? On the theoretical side this is a question of interest that stems from the "vicious circle" hypothesis introduced to experimental psychology (cf. Mowrer, 1960, p. 486) some years ago. On the empirical side it is a question of current interest because experimental psychologists have not yet spelled out the conditions that produce facilitation on the one hand and inhibition on the other.

The present research investigated the effects of punishment on extinction in a setting designed to maximize the possibilities of obtaining facilitation during extinction, According to most theoretical analyses (Mowrer, 1960; Solomon, Kamin, \& Wynne, 1953; and Church, 1963) punishment is more likely to facilitate behavior when the experimental design makes it difficult for $\mathrm{S}$ to discriminate the conditions of punishment from those of avoidance training; and when punishment is administered shortly after the CS onset, the reby maintaining fear previously conditioned to the CS. Discrimination of acquisition and punishment conditions is believed to be most difficult in an apparatus such as the shuttlebox where $\mathrm{S}$ moves from one identical compartment to another and back again in response to a conditioned stimulus. In such an apparatus fear cannot be conditioned to specific geographical cues, such as the start box during conditioning and the goal box during punishment-extinction. Similarly, response latencies in the shuttlebox are typically short, maximizing the likelihood that punishment will condition additional fear to the CS. Another variable that may affect S's ability to discriminate between acquisition and punishment conditions is the degree of overlearning. Early in training the experimental contingencies should be less well differentiated by $S$ thereby leading to greater generalization of punishment-induced fear.

Subjects

The Ss were 264 195-245 gm female Sprague Dawley rats purchased from a commercial supplier.

\section{Apparatus}

An automatic shuttlebox was used (Brush \& Knapp, 1959). The sides of the box were aluminum, the top Plexiglas, and the floor, $3 / 32$ in. stainless steel grids spaced $1 / 2 \mathrm{in.}$ apart. The box was divided into two identical compartments by an aluminum partition equipped with a $3 \times 3$ in., top-hinged door. Photoelectric cells, located $2-3 / 4 \mathrm{in}$. from each side of the partition and 1 in. above the floor were operated by S's passage through the doorway, and served to track S's position and terminate the trial after CS or US had started.

The CS was a $6 \mathrm{w}$ light in combination with a $10 \mathrm{cps}$ click produced by two externally pulsed relays. Bulbs and relays were mounted over the Plexiglas at the end of each compartment. The US was $185 \mathrm{~V}$ delivered to the grids through $150 \mathrm{~K}$. ohms in series with the rat. Shock was scrambled through a 12 bank, 10 position stepping switch.

\section{Procedure}

Five punishment intensities $(45,72,115,185$, and $300 \mathrm{~V})$, two punishment durations (.15 and $2.0 \mathrm{sec}$ ), and three criteria for avoidance training $(2,4$, or 8 consecutive avoidances) were employed. Eight animals were used in each condition. A non-punished group at each training level was included.

Avoidance training. The S was placed in the shuttlebox and after $30 \mathrm{sec}$. the CS came on in the compartment occupied by $\mathrm{S}$. If $\mathrm{S}$ did not change compartments in 5 sec., the US came on and both CS and US continued until $S$ moved to the other compartment. If $S$ changed compartments in the $5 \mathrm{sec}$. CS interval, the US did not come on and S avoided foot shock. Thirty sec. was the intertrial interval used throughout the experiment.

Punishment-extinction. Thirty sec. after S reached the learning criterion, the CS came on and remained on for 5 sec. or until the $S$ moved into the adjacent compartment. If the $S$ did not change compartments in the 5 sec. CS interval, the CS went off, term..1ating the trial. If $S$ crossed to the adjacent compartment within the 5 sec. CS interval, $S$ received the punishing shock appropriate to the group to which it was assigned. Results

Acquisition. The mean number of trials to reach criterion (excluding criterion trials) was 12.7, 15.1, and 22.0 for the 2, 4, and 8 trial groups respectively. An analysis of variance on these data showed training criterion to be significant $(F=11.26, d f=2 / 263, p<.001)$.

Extinction. Figure 1 shows the mean number of latencies under 5 sec. during extinction. No evidence for facilitation by punishmelıv was found at any training level or any punishment intensity. A three-way analysis of 


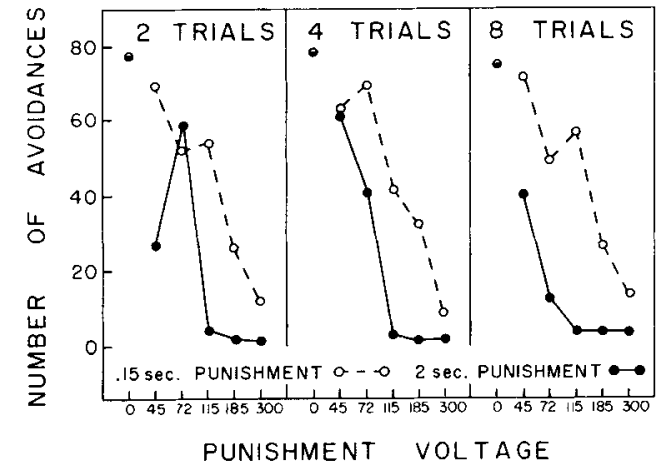

Fig. 1. Mean number of avoidance responses during extinction as a function of level of training and intensity and duration of punishment.

variance on these data showed voltage and duration variables to be significant (voltage: $F=36.08, \mathrm{df}=4 / 210$, $p<.001$; duration: $F=68.55, \mathrm{df}=1 / 210, \mathrm{p}<.001)$. The training-trials variable did not approach significance $(F=.64, d f=2 / 210)$. The duration $x$ voltage interaction was the only significant interaction $(F=41.2, d f=4 / 210$, $\mathrm{p}<.01$ ). A similar analysis on response latencies during extinction showed a similar pattern of significance levels.

To further analyze the results, the 2,4 , and 8 avoidance criterion groups were combined because of the absence of any tendency for the groups to differ during extinction. Figure 2 shows the combined response latencies in 10 trial blocks during extinction for the .15 and $2.0 \mathrm{sec}$. duration punishment groups. Response

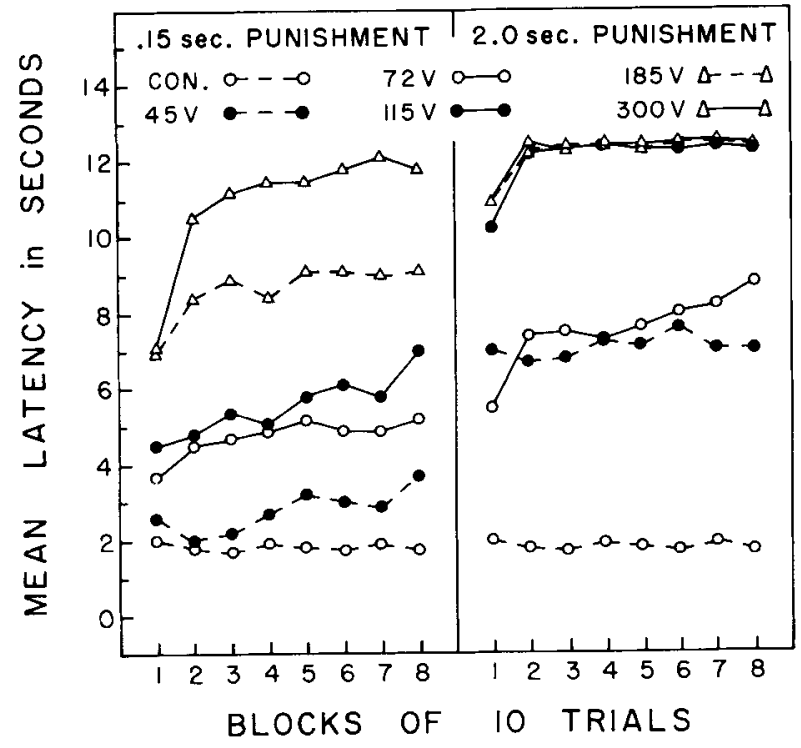

Fig. 2. Mean response latencies in blocks of 10 trials during extinction for .15 and $2.0 \mathrm{sec}$. duration punishment groups at each punishment intensity. Each curve represents the combined latencies of the 2,4 , and 8 avoidance criterion groups. latencies decreased systematically as punishment intensity increased, and the longer the punishment the greater the depression in running speed. There was no evidence of more rapid responding for punished groups than for control groups.

\section{Discussion}

This finding is in direct opposition to that predicted in the introduction and leads us to examine the causes of our failure to find facilitation of responding at any of the conditions employed in this study. First, it is possible that facilitation is found only in highly overtrained animals such as those in the Solomon, Kamin, \& Wynne study (1958). Their animals had had hundreds of successful avoidance conditioning trials before punishment-extinction. Introduction of punishment produced relatively rapid extinction in some dogs but, more typically, an increase in response speeds and prolonged running into the punishing stimulus. Second, in our apparatus the response consisted of running through a small swinging door into another chamber. Movement through the door terminated the CS which consisted of a buzzer and flashing light, and punishment must have acted to condition fear to the response or the cues associated with the response of moving through the door instead of augmenting the fear originally conditioned to the onset of the CS. Thus it is possible that the homogeneous characteristics of the shuttlebox designed to make the conditions of acquisition and punishmentextinction difficult to discriminate were offset by the distinctive characteristics of the CS.

In the present experiment it appears that punishment produced an avoidance gradient conditioned to the response of moving to the adjacent compartment proportionate to the intensity and duration of punishment. When the punishment-induced avoidance gradient exceeded the fear originally conditioned to the CS during avoidance conditioning, cessation of responding resulted. In the larger sense, these results do not deny the existence of facilitation of responding by punishment during extinction of an avoidance response. They do suggest, however, that facilitation of responding by punishment is the exception rather than the rule, and that the conditions which generate punishment-induced facilitation are as yet not delineated.

\section{References}

Brush, F. R., \& Knapp, P. R. A device for detecting and controlling automatic programming of avoidance conditioning in a shuttlebox. Amer. J. Psychol., 1959, 72, 275-278.

Church, R. M. The varied effects of punishment on behavior. Psychol. Rev., 1963, 70, 369-402.

Mowrer, O. H. Learning theory and behavior. New York: Wiley, 1960 .

Solomon, R. L., Kamin, L. J., \& Wynne, L. C. Traumatic avoidance learning: the outcomes of several extinction procedures with dogs. J. abnorm. soc. Psychol., 1953, 48, 291-302.

\section{Notes}

1. This research was supported in part by Public Health Service Grant M-1562 from the National Institutes of Mental Health and in part by National Science Foundation Grant GB 235.

2. Now at the University of Rhode Island. 